\title{
ANÁlISES FÍSICO-gUÍMICAS DE AMOSTRAS DE MÉIS DE FLORES SILVESTRES, DE EUCALIPTO E DE LARANJEIRA, PRODUZIDOS POR Apis mellifera L., 1758 (HYMENOPTERA, APIDAE) NO ESTADO DE SÃo PAUlo. 2. CONTEÚdo de AÇÚCARES E dE PROTEÍNA ${ }^{1}$
}

\author{
Sonia S. KOMATSU², Luís Carlos MARCHINI ${ }^{3, *}$, Augusta C. de C. C. MORETI ${ }^{4}$
}

\section{RESUMO}

Em 94 amostras de méis de flores silvestres, 27 de flores de eucalipto e 34 de flores de laranjeira (totalizando 155 amostras), produzidos por Apis mellifera em 96 municípios do Estado de São Paulo, foram determinados os conteúdos de açúcares e proteínas assim como a porcentagem das amostras que se enquadram dentro das especificações da legislação brasileira. As amostras apresentaram teores de açúcares redutores de 53,2 a 80,0\% (p/p), açúcares redutores totais de 67,8 a $88,3 \%$, de sacarose de 0,1 a $27,4 \%$ e, de proteínas, de 0,0 a $1,6 \mathrm{mg} / \mathrm{mL}$. Das amostras analisadas $99,4 \%$ se enquadram nas especificações da legislação brasileira para qualidade de mel quanto aos valores de açúcares redutores; quanto a sacarose $98,0 \%$ e $39,3 \%$ para proteína.

Palavras-chave: mel; Apis mellifera; análises físico-químicas; açúcares; proteína.

\section{SUMMARY}

PHYSICAL-CHEMICAL ANALYSIS OF HONEYS FROM WILD FLOWERS, EUCALYPTUS FLOWERS AND CITRUS FLOWERS PRODUCED BY Apis mellifera L., 1758 (HYMENOPTERA, APIDAE) IN THE STATE OF SÃO PAULO, BRAZIL. 2. SUGARS AND PROTEIN CONTENTS. A total of 155 honey samples, 94 from wild flowers, 27 from Eucalyptus flowers and 34 from Citrus flowers produced by Apis mellifera were collected from 96 locations of the State of São Paulo. Sugar and protein contents were the parameters determined and the percentage of the honey samples that complied with the Brazilian legislation for honey quality. The results showed that the honeys of these areas of Brazil are likely to be characterized by contents of reducing sugars within the range of 53.2 to $80.0 \%$ (w/w), levels of total reducing sugars of between 67.8 and $88.3 \%$ and from 0.1 to $27.4 \%$ of sucrose. Total protein was estimated at between 0.0 and $1.6 \mathrm{mg} / \mathrm{mL}$. The percentages of honey samples that complied with the Brazilian legislation for honey quality, for each parameter evaluated were: $99.4 \%$ for reducing sugars; $98.0 \%$ for sucrose and $39.3 \%$ for protein.

Keywords: honey; Apis mellifera; physical-chemical analysis; sugars; protein.

\section{1 - INTRODUÇÃO}

O mel, um produto natural elaborado por abelhas a partir do néctar das flores, que é coletado e transformado por elas por meio de dois processos básicos, um físico, evaporação da água e outro químico, adição de enzimas [12] é um dos produtos da colméia mais usados, tanto in natura quanto em diversas formas industrializadas.

É um alimento de fácil digestão e assimilação, constituindo-se numa fonte de energia que contribui para o equilíbrio dos processos biológicos por conter em proporções adequadas, fermentos, vitaminas, ácidos, aminoácidos, substâncias bactericidas e aromáticas [23]. Sua composição varia dependendo da flora visitada e das condições edafo-climáticas da região onde foi produzido.

Dentre os méis comercializados no Estado de São Paulo, os de flores silvestres se destacam por sua maior disponibilidade no mercado, pois este pasto apícola é oferecido às abelhas durante o ano todo. Os reflorestamentos com eucalipto, que têm as flores intensamente visitadas por abelhas, também se constituem em eficientes fontes para a formação de méis apreciados pelos consumidores e, finalmente, os méis de flores de laranjeira são bastante procurados, não só por seu sabor suave, mas também por sua cor clara.

Diante da escassez de informações sobre as ca- racterísticas físico-químicas, necessárias ao incremento da apicultura foi delineado este trabalho com o objetivo de determinar o conteúdo de açúcares e de proteínas de amostras de diferentes origens florais, produzidos por Apis mellifera L., em 96 municípios do Estado de São Paulo, bem como de estabelecer as faixas de variação dos referidos parâmetros e comparar os resultados obtidos com as especificações da legislação brasileira.

\section{2 - MATERIAL E MÉTODOS}

Na Tabela 1 são apresentados os números de amostras de méis de três origens florais coletadas no Estado de São Paulo.

O conteúdo de açúcares redutores (\%), açúcares redutores totais (\%) e sacarose (\%) foram determinados pelo método estabelecido por Somogyi [16]. Foram realizadas duas repetições por amostra e os dados obtidos foram transformados $\sqrt{ } \mathrm{x}+2$ para fins de análise estatística. A proteína do mel foi determinada seguindo-se o método do Laboratório de Controle de Qualidade do Instituto de Zootecnia, que adota a reação de Lund para determinação do referido parâmetro [17]. O fundamento deste método está no fato do ácido tânico precipitar as substâncias albuminóides (proteínas) que são componentes normais do mel. Os dados obtidos foram transformados $\sqrt{x}^{+1}$ para fins de análise estatística e todas

\footnotetext{
${ }^{1}$ Recebido para publicação em 16/05/01. Aceito para publicação em 21/11/01. Parte da tese de Doutorado defendida pela primeira autora em 03/ $04 / 1996$.

${ }^{2}$ ESALQ/USP

${ }^{3}$ Departamento de Entomologia, Fitopatologia e Zoologia Agícola, ESALQ/USP, Av. Pádua Dias, 11 - Cx. Postal O9 - CEP $13148-900$ - Piracicaba, SP

${ }^{4}$ Centro de Etologia, Ambiência e Manejo do Instituto de Zootecnia/SAA, Nova Odessa, SP. Bolsista de Produtividade em pesquisa do CNPq

* A quem a correspondência deve ser enviada.
} 
as médias foram comparadas pelo teste de Tukey em nível de $5 \%$ de probabilidade.

TABELA 1. Número de amostras de méis de flores silvestres (S), de eucalipto (E) e de laranjeira (L) coletadas em diferentes municípios do Estado de São Paulo.

\begin{tabular}{|c|c|c|c|c|c|c|c|}
\hline \multirow{2}{*}{$\begin{array}{l}\text { Municípios do Estado de } \\
\text { São Paulo }\end{array}$} & \multicolumn{3}{|c|}{ Méis } & \multirow{2}{*}{$\begin{array}{l}\text { Municípios do Estado de } \\
\text { São Paulo }\end{array}$} & \multicolumn{3}{|c|}{ Méis } \\
\hline & $\mathrm{S}$ & $\mathrm{E}$ & $\mathrm{L}$ & & $\mathrm{S}$ & $\mathrm{E}$ & $\mathrm{L}$ \\
\hline Altinópolis & 1 & 1 & 1 & Junqueirópolis & 2 & & \\
\hline Amparo & & 1 & & Juquitiba & 1 & & \\
\hline Andradina & 1 & & 1 & Lagoinha & 1 & & \\
\hline Anhembi & & 1 & & Lençóis Paulistas & 1 & 2 & \\
\hline Araçatuba & 2 & 1 & 1 & Limeira & & & 1 \\
\hline Araraquara & & 1 & 2 & Lins & 1 & & 1 \\
\hline Arthur Nogueira & & & 1 & Luiz Antonio & & 2 & \\
\hline Assis & 1 & & & Matão & & & 1 \\
\hline Auriflama & 2 & & 1 & Mirandópolis & 1 & & \\
\hline Avaré & & 2 & & Mirassol & 1 & & \\
\hline Bananal & 1 & & & Mogi Mirim & & & 1 \\
\hline Barretos & 1 & 1 & 2 & Monte Alegre do Sul & 1 & & \\
\hline Bebedouro & & 1 & 5 & Monteiro Loubato & 1 & 1 & \\
\hline Boa Esperança do Sul & 1 & & & Oriente & 1 & & \\
\hline Bofete & 1 & & & Palestina & & & 1 \\
\hline Botucatu & & 1 & & Paraibuna & 1 & & \\
\hline Brotas & 1 & 2 & & Paranapanema & 1 & & \\
\hline Caçapava & 1 & 1 & & Piedade & & & 1 \\
\hline Capão Bonito & 1 & & & Piracaia & 1 & & \\
\hline Casa Branca & & & 1 & Piracicaba & 1 & & \\
\hline Capela do Alto & 1 & & 1 & Piracuama & 1 & & \\
\hline Castilho & 1 & & 1 & Pirassununga & 1 & & \\
\hline Colina & 1 & & & Presidente Prudente & 1 & & \\
\hline Conchal & & & 2 & Redenção da Serra & 2 & & \\
\hline Corumbataí & 1 & & & Rio Claro & 1 & 1 & \\
\hline Cunha & 1 & & & Sabino & 2 & & \\
\hline Descalvado & & & 1 & Santa Cruz do Rio Pardo & 1 & & \\
\hline Espírito Santo do Pinhal & 1 & & & Santa Fé do Sul & 1 & & \\
\hline Estrela d'Oeste & 2 & & & Santo Antonio do Pinhal & 1 & & \\
\hline Gália & 1 & & & São Carlos & 1 & & 1 \\
\hline Getulina & & & 1 & São João da Boa Vista & 1 & & \\
\hline Guarani d'Oeste & 1 & & & São José do Rio Preto & 2 & 1 & 1 \\
\hline Guareí & 2 & & & São Luís do Paraitinga & 2 & & \\
\hline Guarujá & 1 & & & São Pedro & 2 & 1 & \\
\hline Igarapava & 1 & & & São Roque & 3 & & \\
\hline Ilha Solteira & 1 & & & Serra Negra & 5 & & \\
\hline Ipeúna & & 1 & & Sete Barras & 1 & & \\
\hline Itaberá & 1 & & & Tabatinga & & & 1 \\
\hline Itanhaém & 1 & & & Taquaritinga & & & 1 \\
\hline Itapetininga & 1 & 1 & & Taubaté & 1 & & \\
\hline Itapeva & 1 & & & Tietê & 1 & & \\
\hline Itapira & 1 & 1 & & Torrinha & 2 & 1 & 1 \\
\hline Itapirapuã Paulista & 1 & & & Tremembé & 1 & & \\
\hline Ituverava & 1 & & & Ubatuba & 1 & & \\
\hline Jaboticabal & & 1 & & Vargem Grande do Sul & 1 & 1 & 1 \\
\hline Jarinu & 1 & & & Valentin Gentil & 1 & & \\
\hline Joanópolis & 1 & & & Vista Alegre do Alto & 1 & & 1 \\
\hline Jundiaí & 3 & & & Votorantin & 1 & & \\
\hline
\end{tabular}

\section{3 - RESULTADOS E DISCUSSÃo}

Os resultados obtidos para valores de açúcares redutores, açúcares redutores totais e sacarose das amostras de méis produzidos no Estado de São Paulo encontram-se na Tabela 2.

Observa-se que a média dos teores de açúcares redutores nas amostras de méis de laranjeira (74,6\%) foi significativamente maior do que a das amostras de méis silvestres e de eucalipto $(72,6$ e $72,3 \%$, respectivamente) (Tabela 2).
TABELA 2. Valores médios de açúcares redutores $(\% \mathrm{p} / \mathrm{p})$, de açúcares redutores totais $(\% \mathrm{p} / \mathrm{p})$, de sacarose $(\% \mathrm{p} /$ p) e de proteína $(\mathrm{mL})$ das amostras de méis de flores silvestre, de eucalipto e de laranjeira coletadas em municípios do Estado de São Paulo.

\begin{tabular}{lccccc}
\hline \multicolumn{6}{c}{ Açúcares redutores (\% p/p) } \\
\hline Origem floral & $\begin{array}{c}\text { Número de } \\
\text { amostras }\end{array}$ & $\begin{array}{c}\text { Valor } \\
\text { Mínimo }\end{array}$ & Média & $\begin{array}{c}\text { Valor } \\
\text { Máximo }\end{array}$ & $\begin{array}{c}\text { Erro padrão } \\
\text { da média }\end{array}$ \\
\hline Silvestre & 94 & 53,2 & 72,6 & 80,0 & 0,38 \\
Eucalipto & 27 & 67,7 & 72,3 & 77,1 & 0,47 \\
Laranjeira & 34 & 68,6 & 74,6 & 77,9 & 0,33 \\
\hline \multicolumn{7}{c}{ Açúcares redutores totais (\% p/p) } \\
\hline Silvestre & 94 & 68,2 & 75,2 & 82,0 & 0,29 \\
Eucalipto & 27 & 67,8 & 74,9 & 88,3 & 0,69 \\
Laranjeira & 34 & 71,2 & 76,6 & 81,6 & 0,32 \\
\hline \multicolumn{6}{c}{ Sacarose (\% p/p) } \\
Silvestre & 94 & 0,2 & 2,4 & 27,4 & 0,33 \\
Eucalipto & 27 & 0,1 & 2,4 & 15,2 & 0,56 \\
Laranjeira & 34 & 0,3 & 2,0 & 5,2 & 0,22 \\
\hline \multicolumn{6}{c}{ Proteína (mL) } \\
Silvestre & 94 & 0,2 & 0,5 \\
Eucalipto & 27 & 0,0 & 0,6 \\
Laranjeira & 34 & 0,2 & 0,4 \\
\hline
\end{tabular}

FLECHTMANN et al. [9], estudando amostras de méis de flores de eucalipto, de laranjeira e de outras espécies melíferas de sete municípios paulistas, obtiveram valores variando de 80,02 a 83,80\% para conteúdo de açúcares redutores, valores superiores dos encontrados no presente estudo. Autores como TEMIZ [21], HUIDOBRO e SIMAL [13], VIT-OLIVER [26], GÓMEZ et al.[11] e BALDICORONEL, DALL'OGLLIO \& LEZCANO [3] encontraram valores para os teores de açúcares redutores que variaram de 11,2 a 85\%. MORAES e MANTOVANI [15] obtiveram, para amostras de méis de flores de laranjeira 75,90\% e de flores silvestres 75,7\%, valores pouco superiores aos encontrados nas amostras desta pesquisa. CAMPOS [6] estudando méis de origem floral, oriundos de Minas Gerais, observou variações de 60,41 a 77,10\%.

As normas brasileiras estabelecem um mínimo de $65 \%$ de açúcares redutores [5] e desta forma todas as médias apresentadas pelos méis de diferentes origens florais enquadram-se nestas especificações. Se verificarmos, no entanto, o valor de cada amostra, veremos que apenas uma amostra de mel silvestre não se enquadra nas normas. Com base em padrões europeus, THRASYVOULOU, KARANASIOS \& INFANTIDIS [22] tiveram 55\% das amostras de méis aceitas pelas normas oficiais enquanto VIT-OLIVER [26] teve 88,8\% das amostras em conformidade com a legislação venezuelana.

Não ocorreram diferenças significativas nas médias dos teores de açúcares redutores totais para os méis de três diferentes origens florais (silvestre, de eucalipto e de laranjeira) o mesmo ocorrendo para as médias dos teores de sacarose (Tabela 2).

SERRA-I-BONVEHI e CANAS-LLORIA [19] apresentaram um baixo valor de sacarose para mel de eucalipto, fato não verificado no presente trabalho.

Considerando-se as três floradas, altos valores de sacarose, como 27,4 ou 5,2\%, foram constatados por HUIDOBRO e SIMAL [13], que observaram valor de $11 \%$ 
em méis espanhóis. FRIAS-TEJARA e TORRE [10] também obtiveram, para conteúdo de sacarose, um valor bem alto $(22,6 \%)$ de acordo com as especificações oficiais. DOZO [8] teve apenas $1,5 \%$ do total de 66 amostras de méis estudadas com valor de conteúdo de sacarose superior a 8\%. MORAES e MANTOVANI [15] apresentaram valores iguais a $1,3 \%$ e $1,85 \%$ de sacarose, respectivamente, para méis de flores silvestres e de laranjeira, sendo que tais valores médios foram menores que os obtidos nesta pesquisa. VIT et al. [25] em méis da Venezuela constataram valores variando de 0,00 a 4,73 para a sacarose e SPORNS et al. [20], em méis do Canadá, verificaram valores de 0,0 a $6,5 \%$. BALDI CORONEL, DALL'OGLLIO \& LEZCANO [3] e UÑATES et al. [24] encontraram, para méis argentinos, valores de 1 a $13 \%$.

Segundo a legislação brasileira o máximo permitido para valores de sacarose é $10 \%$, desta forma todos os valores médios observados nas amostras enquadramse nas normas brasileiras, embora duas amostras de méis silvestres e uma de mel de eucalipto apresentaram valores superiores aos permitidos. A menor porcentagem de amostras estudadas em conformidade com as especificações brasileiras foi de $96,3 \%$, valor superior a $82,6 \%$ encontrado por VIT-OLIVER [26] e, 55,5\% apresentado por TRASYVOULOU, KARANASIOS \& INFANTIDIS [22], que comparou com padrões europeus.

Não ocorreram diferenças significativas entre as médias dos valores de proteínas das amostras de méis silvestres, de eucalipto e de laranjeira (Tabela 2).

Segundo BATH e SINGH [4] a variação do valor de proteína no mel ocorre em função de sua origem floral, constatando médias 0,036 e 0,65\% para os de flores de Helianthus annus e Eucalyptus lanceiolatus, respectivamente. No Brasil, IMPERATRIZ-FONSECA et al. [14] observaram valores de proteína em méis de eucalipto de 1,92 a $2,76 \%$ e nos méis de Citrus 1,58 enquanto AMARAL et al. [1] encontraram valores de 2,54 e 2,79\% para méis de eucalipto e de laranjeira, respectivamente, valores esses, muito superiores aos observados no presente trabalho $(0,4$ a 0,6\%). CARVALHO et al.[7] encontraram, em amostras de méis do Estado da Bahia, valor médio de 0,44\%. Já ARCHENTI [2] verificou valores muito baixos para os teores de proteínas, da ordem de $0,18 \%$ para os méis argentinos, sendo, desta forma, inferiores aos valores observados neste trabalho. WHITE JÚNIOR e RUDYJ [27] verificaram, nos Estados Unidos, variações de 0,2 a 0,99\% para o teor de proteínas dos méis e PENG e PAN [18] encontraram variações entre 0,048 e 0,42\% para méis de flores de Ziziphus jujuba, Astragalus sinicus, Sesame sp., flor de algodão, dentre outras.

As porcentagens de amostras de méis do Estado de São Paulo que são ou não aceitas segundo as especificações estabelecidas pela legislação brasileira, para conteúdo de proteína, estão ilustradas na Figura 1.

Segundo a legislação brasileira os valores de proteínas em amostras de méis deve estar na faixa de 0,6 a $3,0 \mathrm{~mL}$, desta forma, $63 \%$ das amostras de méis de eucalipto se enquadram nestas normas (Figura 1). A maioria das amostras de méis silvestres e de laranjeira apresenta valores de proteína abaixo desta faixa.

A

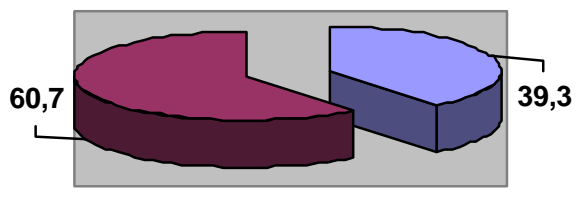

B

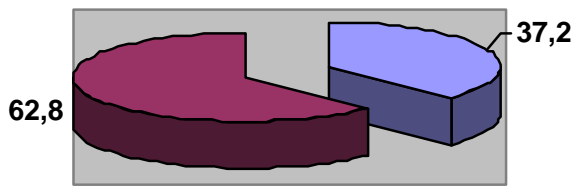

C

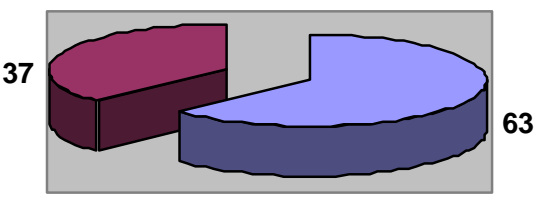

D

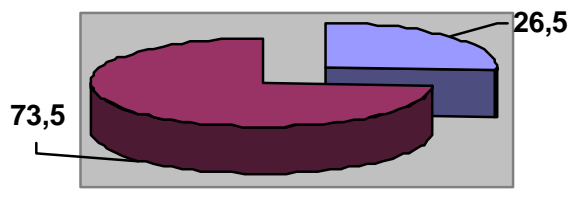

Não Aceitável

Aceitável

FIGURA 1. Porcentagem de amostras, do conjunto de todas as estudadas (A), de méis de flores silvestres (B), de flores de eucalipto(C) e de flores de laranjeira (D), que são aceitáveis, ou não, segundo as especificações da legislação brasileira para valores de proteína.

\section{4 - CONCLUSÕES}

As amostras de méis analisadas apresentam homogeneidade quanto aos parâmetros açúcares reduto- 
res, açúcares redutores totais e sacarose enquadrando-se nas especificações da legislação brasileira para qualidade de mel. Quanto ao parâmetro proteína as amostras de méis apresentam bastante variabilidade, sendo que a maioria das amostras de méis silvestres e de laranjeira tem valores fora das especificações da legislação brasileira para qualidade de mel.

\section{5 - REFERÊNCIAS BIBLIOGRÁFICAS}

[1] AMARAL, A.D.; IMPERATRIZ-FONSECA, V. L.; GIOVANNINI, A.K.; AZOUBEL, M.L. Estudo comparativo entre amostras de méis com origem floral determinada; análise do teor de proteínas, lipídios e carboidratos totais. In: VII CONGRESSO BRASILEIRO DE APICULTURA, Salvador, 1986. Anais... Salvador:CBA, 1986. p. 60.

[2] ARCHENTI, A. Chemical composition of honeys from chubut province (Argentina. Revista de Ciências Agrárias, v. 5, n. 1/4, p. 12-28, 1984.

[3] BALDI-CORONEL, B.; DALL'OGLLIO,A.M.; LEZCANO, S. Caracterización físico químico de las mieles de la Provincia de Entre Rios. Alimentación Latinoamericana, n. 39, p. 39-44, 1993.

[4] BATH, P. K.; SINGH, N. A comparison between Helianthus annuus and Eucalyptus lanceolatus honeys. Bee Wold, v. 80, n. 2, p. 61-69, 1999.

[5] BRASIL. Leis, decretos, etc. Decreto no. 30.691, de 08 de setembro de 1997. Diário Oficial, de 08 de setembro de 1997. Seção 1, p. 19696-19697. Aprova as Normas do Regulamento Técnico para Fixação de Identidade e Qualidade do Mel.

[6] CAMPOS, G. Melato no mel e sua determinação através de diferentes metodologias. Belo Horizonte, 1998. 178p. Tese (Doutorado)- Escola de Veterinária- Universidade Federal de Minas Gerais.

[7] CARVAlHO, C.A.L.; MARCHINI, L.C.; TEIXEIRA. G.M.; OLIVEIRA, P.C.F.; RUBIA, V.R. Características físico-químicas de amostras de méis da Bahia. In: XII CONGRESSO BRASILEIRO DE APICULTURA, Salvador, 1998. Anais....Salvador: Confederação Brasileira de Apicultura, 1998. p.200.

[8] DOZO, A.M.M. Determinacion de azucares em mieles producidas em la província de Buenos Aires, Republica Argentina. In: V CONGRESSO BRASILEIRO DE APICULTURA, III CONGRESSO LATINO-IBERO-AMERICANO DE APICULTURA, Viçosa, 1980. Anais... Viçosa:UFV, 1980. p. 312-316.

[9] FLECHTMANN, C.H.W.; CALDAS FILHO, C.F.; AMARAL, E.; ARZOLLA, J.D.P. Análise de méis do estado de São Paulo. Boletim de Indústria Animal, v. 21, p. 65-73, 1963.

[10] FRIAS TEJERA, I.; TORRE, A.H. DE LA. Physicochemical parameters of honey produced in the province of Santa Cruz de Tenerife. 4. Directly reducing sugars and sucrose. Canarias Apicola, n. 24, p. 4-6, 1991./Resumo em CAB, v. 3A, 1990/1991.

[11] GÓMEZ, R.; CABEZAS, L.; ALCALÁ, M.; FERNÁNDEZSALGUEIRO, J. Determinacion y calculo de la actividad del agua en diferentes muestras de miel. Alimentaria, v. 27, n. 210, p. 33-36, 1990.
[12] HORN, H.; DURÁN, J.E.T.; CORTOPASSI-LAURINO, M.; ISSA, M.R.C.; TOLEDO, V.A.A.; BASTOS, E.; SOARES, A.E.E. Méis brasileiros: resultados de análise físico-químicas e palinológicas. In: XI CONGRESSO BRASILEIRO DE APICULTURA, Piauí, 1996. Anais.... Piauí: CBA, 1996, p. 403-429.

[13] HUIDOBRO, J.F.; SIMAL, J. Determination of sugars in honey. Anales de Bromatologia, v. 36, n. 2, p. 247-264, 1984.

[14] IMPERATRIZ-FONSECA, V. L.; GIOVANNINI, A.; GUIBI, L.S.; AZOUBEL, M.L.; AMARAL, A.D. Preliminary study of Brasilian honeys. In: XXX INTERNATIONAL APICULTURAL CONGRESS, Nagoya, 1987. p.312.

[15] MORAES, R.M.; MANTOVANI, D.M.B. Composição química de méis de diferentes fontes florais. In: VII CONGRESSO BRASILEIRO DE APICULTURA, Salvador, 1986. Programa e resumos. Salvador:CBA, 1986. p.58.

[16] MORAES, R.M.; TEIXEIRA, E.W. Análise de mel (Manual técnico). Pindamonhangaba: Instituto de Zootecnia, 1998. 41p.

[17] NELSON, N. A photometric adaptation of the Somogyi method for the determination of glucose. Journal of Biological Chemistry, v. 153, p. 375, 1944.

[18] PENG, Z.F. \& PAN, J.G. Protein content in honey and its effects on precipitation of beverage. Food science, v. 12 , p. 6-8, 1994.

[19] SERRA-I-BONVEHI, J.; CANAS-LLORIA, S. Physicochemical properties, composition and pollen spectrum of Eucalyptus honey produced in Spain. Apicoltura, n. 4, p. 59-81, 1988./Resumo em CAB, v. 3A, 1990-91.

[20] SPORNS, P.; PLHAK, L.; FRIEDRICH, J. Alberta honey composition. Food Research International, v. 25, n. 2, p. 93-100, 1992.

[21] TEMIZ, A.I. Composition and characteristics of honey from the Izmir region, and effects of different storage methods. Ege Bolge Zirai Arastirma Enstitusu Yayinlari, v. 31, n. 11, p. 113, 1983/Resumo em CAB, 1984-86.

[22] THRASYVOULOU, A.; KARANASIOS, B.; INFANTIDIS, M. Some characteristics of Greek commercial honeys. Scientific Annals of the School of Agriculture, v. 25, p. 51-63, 1982./Resumo em CAB, v. 1, 1984-86.

[23] TREVISAN, M.D.P.; TREVISAN, M.; VIDAL, R. Os produtos das abelhas. SNAP, STA-SEP, FUNDAÇÃO EDUCACIONAL DE BARRETOS. p.24. 1981.

[24] UNÃTES, M.A.; AGUILAR, AB.; PIOLA, H.D. et al. Estudio físico-químico de mieles de la provincia de San Luis República Argentina. Archivos Latinoamericanos de Nutricion, v. 49, n. 2, p. 193-196, 1999.

[25] VIT, P.; MARTORELLI, I.G.; PALACIOS, S.L. Classificación de mieles comerciales venezolanas. Archivos Latinoamericanos de Nutricion, v. 44, n. 1, p. 39-44, 1994.

[26] VIT-OLIVER, P. Classificacion de mieles commerciales venezolanas segun sus caracteristicas físico-quimicas y organolepticas. Merida, 1988. 138p. Thesis - Universidad de Los Andes./Resumo em CAB Abstracts on CD-ROM, v. 3A, 1990-91.

[27] WHITE JÚNIOR, J.W.; RUDYJ, O.N. The protein content of honey. Journal of Apicultural Research, v. 17 , n. 4 , p. 234-244, 1978. 